\title{
HARİZMİ Düşme Riski Ölçeği’nin Psikometrik Özelliklerinin İncelenmesi
}

\author{
Şeyda SEREN INTEPELER* Murat BEKTAŞ** Veysel Karani BARIŞ*** İsa ÇELIK****
}

Öz

Giriş: Hasta düşmelerine neden olan risk faktörlerinin belirlenebilmesi için geçerli ve güvenilir risk değerlendirme araçlarına ihtiyaç vardır. Amaç: Bu araştırma ile HARİZMİ Düşme Riski Ölçeği'nin psikometrik özelliklerinin incelenmesi amaçlanmıştır. Yöntem: Araştırma retrospektif desende vaka-kontrol korelasyonel psikometrik bir çalışmadır. Araştırmanın örneklemini bir üniversite ve bir eğitim araştırma hastanesinde yatarak sağlık hizmeti alan 16 yaş ve altı 480 hasta oluşturmaktadır. Ölçeğin güvenirliği Cronbach alpha katsayısı ve madde toplam puan korelasyonu, geçerliği ise ROC eğrisi, duyarlılık, özgüllük, pozitif öngörü değeri ve negatif öngörü değerleri hesaplanarak değerlendirilmiştir. Bulgular: Ölçeğin Cronbach alpha katsayıs1 .35 olarak hesaplanmış ve ölçekte yer alan maddelerin hepsinin toplam puan ile istatistiksel olarak anlamlı bir korelasyona sahip olduğu saptanmıştır. HARIZZMİ Düşme Riski Ölçeği'nin duyarlılık değeri .43, özgüllük değeri .62, pozitif öngörü değeri .37, negatif öngörü değeri ise .68 olarak hesaplanmıştır. ROC analizi sonucunda ROC Eğrisi Altında Kalan .61 bulunmuştur ( $p=.031 ; \% 95$ Güven Aralığl = .51 - .69). Sonuç: Araştırma kapsamında HARİZMİ Düşme Riski Ölçeği’nin güvenirliğinin ve hastaları ayırım gücünün düşük olduğu saptanmıştır. Sonraki araştırmalarda ölçeğin revize edilerek daha geniş bir örneklemde uygulanması önerilir.

Anahtar Kelimeler: Pediatri, Hasta Düşmesi, Düşme Risk Faktörü, HARİZMİ, Psikometrik Özellikler.

\section{Abstract}

\section{Evaluation of Psychometric Properties of HARIZMI Fall Risk Scale}

Background: Valid and reliable risk assessment tools are needed to determine the risk factors that cause patient falls. Objectives: The aim of this research is to examine the psychometric properties of the HARIZMI Fall Risk Scale. Methods: The research is a case-control correlational psychometric study in a retrospective pattern. The sample of the study consists of 480 patients aged 16 and under who receive health care services in a university and an education and research hospital. The reliability of the scale was evaluated by calculating the Cronbach alpha coefficient and item total score correlation, and its validity by calculating the ROC curve, sensitivity, specificity, positive predictive value and negative predictive values. Results: The Cronbach alpha coefficient of the scale was calculated as .35 and it was found that all the items in the scale had a statistically significant correlation with the total score. HARIZMI Fall Risk Scale's sensitivity value was calculated as .43, specificity value .62, positive predictive value was .37 and negative predictive value was calculated as .68. As a result of the ROC analysis, the Under the Area of ROC Curve was calculated as .61 $(\mathrm{p}=.031,95 \%$ Confidence Intervals $=.51-.69)$. Conclusion: Reliability and discrimination validity of HARIZMI Fall Risk Scale were found low. For future research, it is recommended that the scale is revised and applied in a larger sample.

Key Words: Pediatrics, Patient Falls, Fall Risk Factors, HARIZMI, Psychometric Properties.

Geliş tarihi: 05.05.2020 Kabul tarihi: 29.09.2020

$\mathrm{H}$ astaların zarar görmesinin önlenmesi olarak tanımlanan hasta güvenliği, sağlık bakım hizmetlerinin kişilere verebileceği zararı önlemek amacıyla sağlık kurumları ve çalışanları tarafından alınan önlemlerin tamamını içermektedir (1). Hastanın yere ya da başka bir yüzeye, başka bir kişiye ya da bir cisme çarpmasına neden olan, hasarı olan ya da olmayan ani ve kasıtsız bir iniş olarak tanımlanan düşmeler hasta güvenliğini tehdit eden en önemli olaylardandır $(2,3)$. Düşmeler, hastalarda herhangi bir soruna neden olmayabilirken çeşitli kırıklar, kafa ve omurga yaralanmaları gibi ciddi yaralanma ve ölümler ile de sonuçlanabilmektedir (4). Düşmelerin neden olduğu fiziksel ve psikolojik sorunlar sağlık bakım ihtiyacının artmasına neden olmakta, artan bakım ihtiyacı ise hastaların daha uzun süre hastanede yatmasına ve sağlık hizmetlerinin maliyetlerinin yükselmesine yol açmaktadır. Hastalarda ve sağlık kurumlarında bu şekilde ciddi sonuçlara neden olabilen düşmelerin önlenmesi de büyük önem arz etmektedir $(3,5)$.

Hasta düşme oranları sağlık bakım kalitesini yansıtan önemli bir gösterge olarak kabul edilmektedir. Ülkemizde Sağlık Bakanlığı tarafindan yayımlanan Sağlıkta Kalite Standartları -Hastane kapsamında hasta düşmelerinin önlenmesine yönelik yapılması gereken bazı uygulamalar belirlenmiştir. Bu uygulamalar temel olarak düşme riskinin geçerli ve güvenilir bir ölçüm aracı ile değerlendirilmesini, belirlenen düşme riskine yönelik önlemlerin alınmasını, gerçekleşen düşme olaylarının raporlanmasını ve gerekli iyileştirme çalışmalarının yapılmasını içermektedir (6). Yetişkin hastalar için düşme risk değerlendirmesi ve düşme önleyici programların başarısının incelendiği birçok araştırma bulunmaktadır $(7,8)$. Ancak pediatrik hastalar için aynı durum söz konusu değildir $(9,10)$. Pediatrik hastalar için geliştirilen düşme ölçekleri genellikle yetişkinler için kullanılan ölçekler temel alınarak geliştirilmiştir. Bu nedenle pediatrik hastaların düşme riski istenen düzeyde geçerli ve güvenilir bir şekilde değerlendirememektedir $(3,11)$. Dolayısıyla pediatrik hastalara özgü düşme risk faktörlerinin ve önleyici girişimlerin belirleneceği daha fazla araştırmaya gereksinim duyulmaktadır.

Çocukların, büyürken, yürümeye başlarken, yeni koordinasyon ve beceriler kazanırken çevrelerindeki sınırlamaların yeterince farkında olmadıkları için, düşmeye eğilimleri yetişkinlere göre daha fazladır. Bu durum büyüme ve gelişme dönemindeki tüm çocukların düşme riski altında olduğunu göstermektedir. Dolayısıyla düşme kaynaklı yaralanma riskini en aza indirmek için önleme stratejilerinin planlanması, uygulanması ve değerlendirilmesi gerekmektedir (12). Yapılan araştırmalarda çocuk hastalar için hastanelerde yaşanan düşmeler ile ilgili; nörolojik hastalıklar, yaş, cinsiyet, bilişsel gelişim, düşme öyküsü, ilaç kullanımı, cerrahi girişimler, yardımcı araç kullanımı, bağımlılık düzeyi, anne-babanın çocuğun yanında bulunma durumu *Profesör Doktor, Dokuz Eylül Üniversitesi Hemşirelik Fakültesi Hemşirelikte Yönetim Anabilim Dalı, İnciraltı/İzmir Orcid: https://orcid.org/0000-0001-8615$\underline{9765} * *$ Doçent Doktor, Dokuz Eylül Üniversitesi Hemşirelik Fakültesi Çocuk Sağlığı ve Hastalıkları Hemşireliği Anabilim Dalı, İnciraltı/İzmir Orcid: https://orcid.org/0000-0003-3327-8204 *** Araştırma Görevlisi, Dokuz Eylül Üniversitesi Hemşirelik Fakültesi **** Araştırma Görevlisi, Dokuz Eylül Üniversitesi Hemşirelik Fakültesi Çocuk Sağlığı ve Hastalıkları Hemşireliği Anabilim Dalı, İnciralt1/İzmir Orcid: https://orcid.org/0000-0003-3381-2286 gibi bazı risk faktörleri belirtilmiştir $(13,14)$. 
Hasta düşmelerinin önlenmesi doğru risk değerlendirmesi ile başlar. Bu nedenle önleme ve bakım kalitesinde sürekli iyileştirmeler yapmak için geçerli ve güvenilir bir risk değerlendirme aracının kullanılması gerekir (3). Murray ve arkadaşları (2016) gerçekleştirdikleri araştırmada 26 hastanede kullanılan pediatrik düşme riski ölçeğini incelemişlerdir. Araştırmada, ölçeklerin büyük bir çoğunluğunun doğrulama çalışmalarının yapılmamış olduğunu, geliştirilirken sınırlı sayıda hasta verisinin kullanıldığını dolayısıyla da ölçeklerin geçerliklerinin düşük olduğunu saptamışlardır (12). Risk değerlendirmenin hasta düşmelerinin önlemesinde başarı sağlayabilmesi için risk değerlendirme aracının hastalarda var olan riskleri doğru saptayabilmesi ve düşme riski yüksek olan hastaları ayırt edebilmesi gerekmektedir. Dolayısı ile doğru hastaya doğru düşme önleyici girişimi belirleyebilmek için kullanılan düşme risk değerlendirme aracının güvenilir, geçerli ve yeterli duyarlık ve özgüllüğe sahip olması önem arz etmektedir $(15,16)$. Aksi takdirde kullanılan risk değerlendirme aracı, uygulanan düşme önleyici programların başarısız olmasına neden olabilir (17).

Alan yazında pediatrik hastaların düşme risk değerlendirmesinde kullanılabilecek birçok risk değerlendirme aracı bulunmaktadır (2,7,13). Ancak bu ölçeklerden herhangi biri çocuk hastaların düşme risklerinin değerlendirilmesinde altın standart olarak kabul edilmemiştir. Ölçekler farklı popülasyonlarda farklı sonuçlar vermektedirler. Ülkemizde çocuk hastaların düşme risklerinin değerlendirilmesinde yaygın olarak Sağlık Bakanlığı tarafından geliştirilen HARİZMİ Düşme Riski Ölçeği kullanılmaktadır (6). Ancak HARİZİ Düşme Riski Ölçeği’nin güvenirlik ve geçerliğinin değerlendirildiği sadece bir çalışmaya ulaşılmıştır (18). Ölçeğin farklı ve geniş popülasyonlardaki sonuçlarının incelenmesi ölçeğin geçerlik ve güvenirliği ile ilgili daha doğru sonuçlar verecektir. Elde edilecek bu sonuçlar ölçeğin daha etkili kullanılmasına firsat tanıyarak düşme önleyici programların başarısının artmasına da katkı sağlayacaktır.

\section{Araştırmanın Amacı}

Bu araştırma ile HARİZİ Düşme Riski Ölçeği’nin psikometrik özelliklerinin incelenmesi amaçlanmıştır.

\section{Yöntem}

\section{Araştırmanın Tipi}

Araştırma retrospektif desende vaka-kontrol korelasyonel psikometrik bir çalışmadır.

\section{Araştırmanın Yeri}

Araştırma İzmir ilindeki bir üniversite ve bir eğitim araştırma hastanesinde Mayıs 2019 - Ocak 2020 tarihleri arasında gerçekleştirilmiştir. Yatak kapasitesi üniversite hastanesinde 1080, eğitim araştırma hastanesine 910 iken çalışan hemşire sayısı üniversite hastanesinde 802, eğitim araştırma hastanesinde ise 870'tir. Her iki hastanede de kalite çalışmaları kapsamında düşmeler kalite birimi tarafından düzenli olarak izlenmektedir.

\section{Araştırmanın Örneklemi}

Araştırmanın hedef popülasyonu gerçekleştirildiği hastanelerde yatarak sağlık hizmeti alan 16 yaş ve altındaki hastalardır. Araştırma sonuçlarının genellenebilirliğini artırabilmek için güvenirlik ve geçerlik analizleri farklı örneklemlerden elde edilen veriler kullanılarak gerçekleştirilmiştir.

Güvenirliğin test edilmesi için araştırmanın gerçekleştirildiği hastanelerde Mayıs 2019 - Ocak 2020 tarihleri arasında yatarak sağlık hizmeti alan 16 yaş ve altı hastalar araştırmaya dahil edilmiştir. Bu kapsamda hastanelerdeki farklı 17 klinikte yatan toplam 324 hastaya ulaşılmıştır. Geçerlik ve güvenirlik çalışmalarında örneklem hesaplanırken 100 altında örneklem çok düşük, 100-200 arasında düşük, 200-300 arası orta, 300-500 arası iyi, 500-1000 arası çok iyi, 1000 ve üstü mükemmel olarak kabul edilmektedir (19). Bu çalışmada, alan yazındaki bilgiye göre ulaşılan örneklem sayısı iyi düzeydedir.

Geçerlik analizleri kapsamında araştırmanın gerçekleştirildiği hastanelerde Ocak 2016 - Temmuz 2019 y1lı içerisinde düşme deneyimi yaşayan hastalar vaka grubu olarak kabul edilmiştir. Belirlenen kriterler doğrultusunda vaka grubundaki hastalar ile eşleştirilen ve hastanede yattığı süre içerisinde düşme deneyimi yaşamayan hastalar ise kontrol grubu olarak belirlenmiştir. Araştırma kapsamında ulaşılması hedeflenen vaka grubu sayısı Flahault ve arkadaşlarının (2005) yayımlamış olduğu duyarlık ve geçerlik çalışmaları için örneklem hesaplama kriterleri temel alınarak hesaplanmıştır (20). Buna göre araştırma kapsamında belirlenen kriterler doğrultusunda (duyarlık ve geçerlik değeri hedefi $=.90, \% 95$ güven aralığındaki en düşük duyarlılık değeri hedefi $=.70)$ ulaşılması hedeflenen vaka grubu sayısı 41 olarak belirlenmiştir. Araştırma kapsamında vaka - kontrol eşleştirme oranı 1:2 olarak belirlendiği için hedeflenen en düşük kontrol grubu sayısı ise 82 olarak hesaplanmıştır. Vaka ve kontrol grubu dahil olma ve dışlama kriterleri Tablo 1. de yer almaktadır.

\section{Tablo 1. Vaka ve Kontrol Grubu Dahil Olma ve Dıșlama Kriterleri}

\begin{tabular}{|c|c|c|}
\hline & Vaka Grubu & Kontrol Grubu \\
\hline $\begin{array}{c}\text { Dahil Olma } \\
\text { Kriterleri }\end{array}$ & $\begin{array}{l}\text { - Hastanın hastanede sağlık hizmeti aldığı } \\
\text { süre içerisinde düşme deneyimi yaşamış } \\
\text { olması. } \\
\text { - Gerçekleşen düşme olayının bildiriminin } \\
\text { yapılmış olması. }\end{array}$ & $\begin{array}{l}\text { - Hastanın çalışmanın gerçekleştirildiği hastanelerde } \\
\text { yatarak sağlık hizmeti almış olması. } \\
\text { - Eşleştirildiği düşen hasta ile; } \\
\text { - Aynı yatış tanısına sahip olması, } \\
\text { - } \quad \text { Aynı yaşlarda ( } \pm 5) \text { olması }(0-2 \text { yaş arası çocuklarda } \\
\quad \pm 1 \text { Yaş), } \\
\text { - Aynı cinsiyette olması, } \\
\text { - Aynı hastanede ve serviste tedavi görmesi } \\
\text { - Düşen hasta ile yatış tarihleri arasındaki zaman } \\
\text { farkının bir yıldan az olması. (Örneğin vaka } \\
\text { grubundaki hasta 2018 y1lında sağlik hizmeti almış ise } \\
\text { kontrol grubundaki hasta, 2017-2019 tarihleri }\end{array}$ \\
\hline
\end{tabular}


Dışlama Kriterleri
- Hastanın bilgilerine (tanısı, hastanede yattığı süre içerisinde yapılan işlemler vb.) ulaşılamaması.

- Hastanın belirlenen eşleştirme kriterleri doğrultusunda düşme deneyimi yaşamamış herhangi bir hasta ile eşleştirilememesi.
- Hastanın bilgilerine (tanısı, hastanede yattığı süre içerisinde yapılan işlemler vb.) ulaşılamaması.

Belirlenen kriterlere göre düşme deneyimi yaşayan toplam 53 hasta araştırmaya dahil edilmiştir. Eşleştirme kriterleri temel alınarak bu hastalar toplam 103 kontrol grubu hastası ile eşleştirilmiştir. Dolayısıyla vaka ve kontrol grubunu oluşturan toplam 156 hasta HARIZMİ Düşme Riski Ölçeği’nin geçerlik analizi örneklemini de oluşturmaktadır.

\section{Veri Toplama Araçları}

Araştırma kapsamında katılımcıların genel ve düşme olayı özellikleri için Tanımlayıcı ve Düşme Bilgileri Veri Toplama Formu, düşme risklerinin değerlendirilmesi için ise HARİZMİ Düşme Riski Ölçeği kullanılmıştır.

- Tanımlayıcı ve Düşme Bilgileri Veri Toplama Formu: Hastaların yaşı, tanısı, cinsiyeti, yatış tarihi, taburculuk tarihi gibi tanımlayıcı bilgileri, düşme gerçekleşme durumu ve HARİZMİ Düşme Riski Ölçeği toplam puanı gibi toplam 10 sorunun yer aldığı form araştırmacılar tarafından oluşturulmuştur.

- HARİMI Düşme Riski Ölçeği: Sağlık Bakanlığı tarafından geliştirilen HARİZMİ Düşme Riski Ölçeği düşme riskini sorgulayan dokuz maddeden oluşmaktadır (nörolojik hastalık/semptom, oksijenlenme değişikliği, düşme riski açısından özellikli hastalığı/semptomu, uygun yatakta yatırılma durumu, görme engeli, hastaya bağlı ekipmanlar, ayakta/yürürken fiziksel desteğe gereksinim duyma durumu, post-op dönemde olma ve riskli ilaç kullanımı). Risk faktörlerinin değerlendirilmesi sonucu elde edilen toplam puan üzerinden düșük ve yüksek olmak üzere iki risk düzeyi belirlenmiștir. Eğer toplam puan 15'in altında ise hastanın düşme riski düşük, 15 ve üzeri ise hastanın düşme riski yüksek kabul edilmektedir (6).

\section{Verilerin Toplanmast}

Araştırmanın gerçekleştirildiği hastanelerde düşme deneyimi yaşayan hastalara, hastanelerin kalite birimlerinden ve hastane bilgi yönetim sistemlerinden ulaşılmıştır. Araştırmanın örneklemini oluşturan hastalara ait bilgilere ise hastanelerin bilgi yönetim sistemlerinden ve hastane arşivlerinde yer alan hasta dosyalarından ulaşılmıştır. Araştırma kapsamında tüm veriler araştırmacılar tarafından toplanmıştır ancak hastaların HARİZMI Düşme Riski Ölçeği kullanılarak risk değerlendirmesi araştırmacılar tarafından yapılmamış, hemşirelerin gerçekleştirip kayıt altına aldığı değerlendirme sonuçları kullanılmıştır.

\section{Verilerin Değerlendirilmesi}

HARIZMİ Düşme Riski Ölçeği'nin güvenirliği Cronbach alpha katsayısı ve madde toplam puan korelasyon analizi ile geçerliği ise alıcı işlem karakteristiği (ROC eğrisi), Duyarlılık, Özgüllük, Pozitif Öngörü Değeri ve Negatif Öngörü değerleri hesaplanarak değerlendirilmiştir. Gerçeklik analizi için kullanılan kavramlara ait formüller Şekil 1.'de yer almaktadır. Araştırma kapsamında korelasyon analizi için Pearson korelasyon analizi, risk grubuna göre düşme oranlarının karşılaştırılmasında ki kare analizi, düşen ve düşmeyen hastaların HARİZMİ ölçek puanlarının karşılaştırılmasında ise bağımsız gruplarda t testi kullanılmıştır.

\begin{tabular}{|c|c|c|c|c|}
\hline & & \multicolumn{2}{|c|}{$\begin{array}{c}\text { Düssme Riski } \\
\text { Durumu }\end{array}$} & \\
\hline & & $\begin{array}{c}\text { Yüksek Risk } \\
\text { (HARİZMI } \geq 15 \text { ) }\end{array}$ & $\begin{array}{c}\text { Düşük Risk } \\
(\text { HARİZMİ < 15) }\end{array}$ & \\
\hline \multirow{2}{*}{$\begin{array}{l}\text { Düsşme } \\
\text { Durumu }\end{array}$} & Düşme Var & $\begin{array}{l}\text { Gerçek Pozitif } \\
\text { (GP) }\end{array}$ & $\begin{array}{l}\text { Yanlış Negatif } \\
\text { (YN) }\end{array}$ & Duyarlılık $=\frac{G P}{G P+Y N}$ \\
\hline & Düssme Yok & $\begin{array}{l}\text { Yanlış Pozitif } \\
\text { (YP) }\end{array}$ & $\begin{array}{l}\text { Doğru Negatif } \\
\text { (DN) }\end{array}$ & Özgüllük $=\frac{D N}{Y P+D N}$ \\
\hline & & $\mathrm{PÖD}=\frac{G P}{G P+Y P}$ & $\mathrm{NÖD}=\frac{D N}{Y N+D N}$ & \\
\hline
\end{tabular}

PÖD: Pozitif Öngörü Değeri NÖD: Negatif Öngörü Değeri

Jung H, Park HA. Testing the predictive validity of the Hendrich II fall risk model, Western Journal of Nursing Research, 2018;40(12), 1785-1799 (27).

\section{Şekil 1. Gerçeklik analizi kavramları formülleri}


Araştırma

\section{Araştırmanın Etik Yönü}

Araştırmanın yürütüldüğü kurumlardan kurum izni (Sayı: 72292585-10.99-E.27811 Tarih: 09/04/2019; Sayı: 26325996 Tarih: 28/02/2019) ve bir üniversitenin girişimsel olmayan araştırmalar etik kurulundan ise etik onay alınmıştır (Karar No: 2019/18-40 Tarih: 17/07/2019). Ayrıca ölçek Sağlık Bakanlığı tarafından geliştirildiği için kullanım izin yazısı bakanlıktan alınmıştır (Sayı: 26325996 Tarih: 28/02/2019). Makalenin tüm aşamalarında araştırma ve yayın etiğine uyulmuştur.

\section{Bulgular}

Araştırma kapsamında güvenirlik ve geçerlik analizleri farklı hastalara ait veriler ile gerçekleştirildiği için hastaların tanımlayıcı özellikleri birbirinden ayrı olarak sunulmuştur. Araştırmanın örneklem grubuna ait tanımlayıcı bilgiler Tablo 2.'de yer almaktadır.

Tablo 2. Araştırma Örneklemi Tanımlayıcı Bilgileri

\begin{tabular}{|c|c|c|c|c|c|c|}
\hline \multirow[t]{2}{*}{ Yaş } & \multicolumn{2}{|c|}{$\begin{array}{c}\text { Güvenirlik Grubu } \\
4.94 \pm 5.19\end{array}$} & \multicolumn{2}{|c|}{$\begin{array}{c}\text { Vaka Grubu } \\
3.91 \pm 4.63\end{array}$} & \multicolumn{2}{|c|}{$\begin{array}{c}\text { Kontrol Grubu } \\
3.69 \pm 4.32\end{array}$} \\
\hline & $\mathbf{n}$ & $\%$ & $\mathbf{n}$ & $\%$ & $\mathbf{n}$ & $\%$ \\
\hline \multicolumn{7}{|l|}{ Cinsiyet } \\
\hline Kadın & 147 & 45.4 & 25 & 47.2 & 51 & 49.5 \\
\hline Erkek & 177 & 54.6 & 28 & 52.8 & 52 & 55.5 \\
\hline \multicolumn{7}{|l|}{ Hastane } \\
\hline Eğitim Araştırma & 156 & 48.1 & 17 & 32.1 & 34 & 33 \\
\hline Üniversite & 168 & 51.9 & 36 & 67.9 & 69 & 67 \\
\hline \multicolumn{7}{|l|}{ Birim } \\
\hline Acil Servis & - & - & 5 & 9.43 & 7 & 6.80 \\
\hline Cerrahi Birimler & 34 & 10.49 & 14 & 26.42 & 28 & 27.18 \\
\hline Yoğun Bakımlar & 53 & 16.36 & 3 & 5.66 & 6 & 5.83 \\
\hline Dahili Birimler & 237 & 73.15 & 31 & 58.49 & 62 & 60.19 \\
\hline Toplam & 324 & 100 & 53 & 100 & 103 & 100 \\
\hline
\end{tabular}

Güvenirlik analizlerinin gerçekleştirildiği hastaların yaş ortalaması $4.94 \pm 5.19$ olarak hesaplanmıştır. Hastaların \%45.4 (147)'ü kadın, \%54.6 (177)'sı erkek olup, \%48.1 (156)'i eğitim araştırma hastanesinde, \%51.9 (168)’u üniversite hastanesinde, \%10.49 (34)’u cerrahi birimlerde, \%16.36 (53)'sı yoğun bakım birimlerinde, \%73.15 (237)’i dahili birimlerde yatan hastalardan oluşmaktadır.

Geçerlik analizleri kapsamında yaş ortalaması $3.91 \pm 4.63$ olan vaka grubu hastalarının hastanede kalış süresi ortalaması $15.05 \pm 20.91$ gündür. Kadın hasta oranının \%47.2 (25), erkek hasta oranının ise \%52.8 (28) olan vaka grubu hastalarının \%32.1 (17)'i eğitim araştırma hastanesinde, \%67.9 (36)'u üniversite hastanesinde, \%5.66 (3)'s1 yoğun bakım birimlerinde, \%9.43 (5)’ü acil serviste, \%26.42 (14)’si cerrahi birimlerde, \%58.49 (31)’u ise dahili birimlerde yatarak sağlık hizmeti almıştır. Vaka grubunu oluşturan hasta düşmesi olaylarının \%65.4 (34)'ü hastaneye yatışından sonraki ilk altı gün içerisinde gerçekleşmiştir.

Yaş ortalaması $3.69 \pm 4.32$ olan kontrol grubu hastaları ortalama $7.91 \pm 10.90$ gün yatarak sağlık hizmeti almıştır. Kontrol grubunun 49.5 (51)’i kadın, 50.5 (52)’i erkek olup hastaların \%33 (34)'ü eğitim araştırma hastanesinde, \%67 (69)’si üniversite hastanesinde, \%5.83 (6)'ü yoğun bakımlarda, \%6.80 (7)’i acil serviste, \%27.18 (28)’i cerrahi birimlerde, \%60.19 (62)’u ise dahili birimlerde yatan hastalardan oluşmaktadır.

\section{Güvenirlik İle Ilgili Bulgular}

Güvenirlik analizleri kapsamında HARİZMİ Düşme Riski Ölçeği’nin Cronbach alpha katsayısı .35 olarak hesaplanmıştır. Ölçekteki tüm maddelerin toplam puan ile istatistiksel olarak anlamlı bir korelasyona sahip olduğu saptanmış korelasyon değerleri .17 - .77 arasında hesaplanmıştır. Korelasyon katsayısı .20'den düşük olan maddeler "Görme engeli var $(\mathrm{r}=.16$, p = .003)”, “Hasta post-op, ilk 48 saatlik dönemde $(\mathrm{r}=.18, \mathrm{p}=.001)$ ” maddeleridir.

Geçerlik ile İlgili Bulgular

Hastaların risk grubuna göre düşme oranları Tablo 3.'de yer almaktadır.

Tablo 3. Kesme Noktası 15 Puan'a Göre Hastaların Düşme Riski Durumu İle Düşme Durumlarının Karşılaştırılması

\begin{tabular}{|c|c|c|c|c|c|c|c|c|}
\hline \multirow{3}{*}{$\begin{array}{l}\text { ÖLÇEC̆E GÖRE } \\
\text { DÜŞME RİSKİ }\end{array}$} & \multicolumn{6}{|c|}{ DÜŞME DURUMU } & \multirow{3}{*}{$\mathrm{x}^{2^{*}}$} & \multirow{3}{*}{$\mathbf{p}$} \\
\hline & \multicolumn{2}{|c|}{ Düsstü } & \multicolumn{2}{|c|}{ Düşmedi } & \multicolumn{2}{|c|}{ Toplam } & & \\
\hline & $\mathbf{n}$ & $\%$ & $\mathbf{n}$ & $\%$ & $\mathbf{n}$ & $\%$ & & \\
\hline Yüksek & 23 & 37.1 & 39 & 62.9 & 62 & 100 & .447 & .504 \\
\hline Düşük & 30 & 31.9 & 64 & 68.1 & 94 & 100 & & \\
\hline Toplam & 53 & 0.34 & 103 & 0.66 & 156 & 100 & & \\
\hline
\end{tabular}

* Ki-kare analizi 
Sağlık Bakanlığı tarafından geliştirilen HARIZMİ Düşme Riski Ölçeği’nin kesme noktası 15 puan olarak belirlenmiştir. Belirlenen bu kesme noktasına göre geçerlik örneklemindeki hastaların \%39.74 (62)’ü düşme riski yüksek, \%60.26 (94)'sı ise düşme riski düşük olarak değerlendirilmiştir. Yüksek riskli olarak değerlendirilen 62 hastanın \%37.1 (23)’i düşme deneyimi yaşarken, düşme riski düşük olarak değerlendirilen 94 hastanın \%31.9 (30)'u düşme deneyimi yaşamıştır. Risk grubuna göre düşme sayıları karşılaştırıldığında, yüksek riskli hastalar ile düşük riskli hastaların düşme sayıları arasında istatistiksel olarak anlamlı bir fark saptanmamıştır $\left(\mathrm{x}^{2}=4.447, \mathrm{p}=.504\right)$. Bu veriler doğrultusunda HARİZMİ Düşme Riski Ölçeği'nin duyarlılık değeri .43, özgüllük değeri .62, pozitif öngörü değeri .37, negatif öngörü değeri ise .68 olarak hesaplanmıştır.

Tablo 4. Vaka ve Kontrol Grubu Hastaların HARIZMI Ölçek Puan Ortalamalarının Karşılaştırılması

\begin{tabular}{lccccc}
\multicolumn{1}{c}{ Hasta Grubu } & $\begin{array}{c}\text { Hasta } \\
\text { sayısı }\end{array}$ & $\begin{array}{c}\text { HARIZMI Ölçek Puanı } \\
\text { Ortalamaları }\end{array}$ & Standart Sapma & Puan Farkı & $\mathbf{t}^{*}$ \\
Vaka grubu & 53 & 12.8491 & 9.34467 & 3.218 & 2.204 \\
Kontrol grubu & 103 & 9.6311 & 8.25452 & & .029 \\
\hline
\end{tabular}

\section{*Student's t-test}

Vaka grubu hastalarının HARİZİ Düşme Riski Ölçeği puan ortalaması $12.85 \pm 9.35$, kontrol grubu hastaların puan ortalaması ise $9.63 \pm 8.25$ olarak hesaplanmış ve aradaki farkın istatistiksel olarak anlamlı olduğu saptanmıştır $(\mathrm{t}=2.204$, $\mathrm{p}=$ .029). Vaka ve kontrol grubu hastalarının ölçek puan ortalamaları ile ilgili bilgiler Tablo 4.'de sunulmuştur. Ölçeğin ayırım gücünü değerlendirebilmek için gerçekleştirilen ROC analizi sonucuna belirlenen ROC Eğrisi grafiği Grafik 1.'de yer almaktadır. Analiz sonucunda göre ROC Eğrisi Altında Kalan Alan .61 bulunmuştur ( $p=.031 ; \% 95$ Güven Aralığı = .51 - .69).

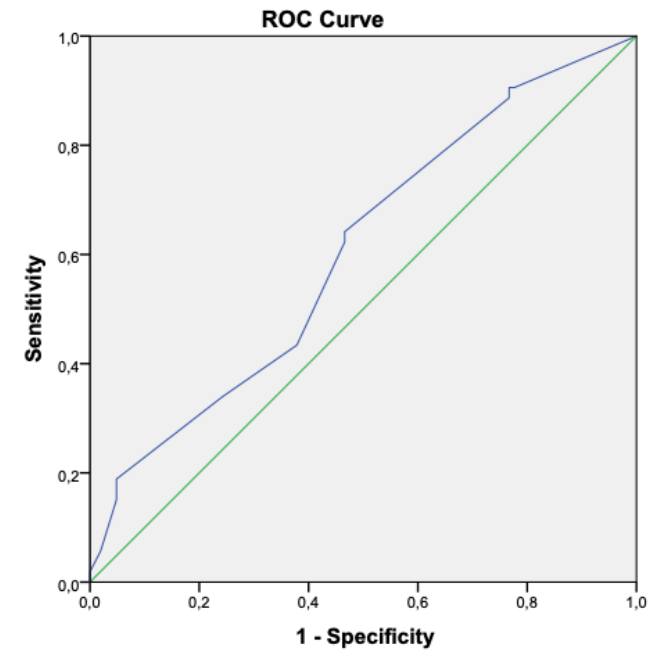

Grafik 1. ROC Ĕ̈risi

Gerçekleştirilen ROC analizi sonucunda elde edilen farklı kesme noktalarına göre HARİZMİ Düşme Riski Ölçeği duyarlılık ve özgüllük değerleri Tablo 5.'te sunulmuştur.

Tablo 5. HARIZMİ Ölçeği Farklı Kesme Noktalarına Göre Duyarlılık ve Özgüllük Değerleri

\begin{tabular}{ccc}
\hline Ölçek Kesme Puanı & Duyarlılık & Özgüllük \\
-1.00 & 1.00 & 1.00 \\
1.00 & .90 & .77 \\
2.50 & .90 & .76 \\
4.00 & .88 & .76 \\
$\mathbf{6 . 0 0}$ &. $\mathbf{6 4}$ &. $\mathbf{4 6}$ \\
8.50 & .62 & .46 \\
12.50 & .43 & .37 \\
17.50 & .34 & .24 \\
21.50 & .18 & .04 \\
24.00 & .15 & .04 \\
27.50 & .05 & .01 \\
35.00 & .01 & .00 \\
41.00 & .00 & .00 \\
\hline
\end{tabular}


Buna göre en uygun kesme noktası değerinin 6 olduğuna karar verilmiştir. Belirlenen yeni kesme noktasına göre ölçeğin duyarlılık değeri .64, özgüllük değeri .53, pozitif öngörü değeri .41, negatif öngörü değeri ise .74’tür.

\section{Tartıșma}

Ölçüm aracının güvenirliği kapsamında en önemli göstergelerden birisi Cronbach alpha katsayısıdır. Cronbach alpha katsayısı .40 'tan küçükse "ölçek güvenilir değil”", .40 - .59 arasındaysa "düşük güvenilir", .60 - .79 arasındaysa "oldukça güvenilir", .80 1.00 arasındaysa "yüksek derecede güvenilir" olarak kabul edilmektedir (21). Araştırma kapsamında HARİZMİ Düşme Riski Ölçeği’nin Cronbach alpha katsayısı .40 'dan düşük saptanmıştır. Dolayısıyla bu sonuç ölçeğin güvenilir olmadığının bir göstergesi olarak kabul edilebilir. Ölçeğin Cronbach alpha değerinin düşük olmasına maddelerin birbirinden bağımsız olması, likert tipi bir ölçek olmaması ve maddelerin puan yükleri arasındaki farklılıkların yol açttğı düşünülebilir. Ölçekte yer alan maddelerin ölçülen yapı ile uygunluğu madde toplam puan korelasyon analizi ile değerlendirilmektedir. Maddenin toplam puan ile korelasyonunun yüksek olması ölçülen yapıya uygunluğunun da yüksek olduğunu göstermektedir. Bununla birlikte maddenin yapı ile uygun olduğu yorumunu yapabilmek için madde toplam puan korelasyon değerinin .20'den yüksek olması gerekmektedir (21-23). Araştırma kapsamında ölçekte yer alan iki maddenin korelasyon katsayısı .20'den düşük saptanmıştır. Bu sonuç maddelerin ölçülen yapı ile uygun olmadığının bir göstergesidir, ancak maddelerin düşmelere neden olduğu daha önceki çalışmalarda saptandığı için maddelerin ölçekten çıkarılması ya da yeniden düzenlenmesi için daha detaylı bir araştırmaya gereksinim bulunmaktadır (24-26).

Tanı araçlarının başarısı hasta olan ve olmayan insanları ayırt edebilme yeteneğine göre değerlendirilmektedir. Tanı araçlarının bu yeteneği ise duyarlılık, özgüllük, pozitif öngörü değeri, negatif öngörü değeri ve ROC Eğrisi Altında Kalan alan ile ölçülmektedir $(15,27,28)$. Duyarlılık tanı aracının hasta/riskli olan kişileri belirleyebilme yeteneği, özgüllük ise hasta olmayan kişileri belirleyebilme yeteneği olarak tanımlanmaktadır. Tanı testinin başarısının değerlendirilmesinde oldukça önemli olan bu iki değer birbiri ile ters ilişkilidir $(27,28)$. Düşme risk değerlendirmesindeki öncelikli amaç düşme riski yüksek olan hastaları belirleyerek hastaların risk faktörlerine özgü girişimler ile düşmelerinin engellenmesidir. Bu nedenle düşme risk değerlendirme aracının duyarlılık ve özgüllük seviyelerinin dengeli olması koşulu ile birlikte duyarlık seviyesinin daha yüksek olması gerekmektedir (29,30). Gerçekleştirilen analizler sonucunda HARİMİ Düşme Riski Ölçeği'nin duyarlık değerinin özgüllük değerinden daha düşük olduğu saptanmıştır. Yöntem ve arkadaşları (2017) tarafindan gerçekleştirilen araştırmada da benzer şekilde duyarlılık değeri (.12), özgüllük değerinden (93.2) daha düşük hesaplanmıştır (18). Bu duruma, ölçeğin hasta düşmelerine neden olan birçok risk faktörünü içermemesi ve kesme noktası puanının yüksek olmasının yol açtı̆̆ı düşünülmektedir $(15,30)$. Ölçeğin duyarlılık seviyesinin düşük olması riski yüksek olan hastaların belirlenememesine ve dolayısıyla da bu hastalara gerekli önleyici girişimlerin uygulanamamasına neden olmaktadır. $\mathrm{Bu}$ durumda hastanelerde gerçekleştirilen düşme önleyici programların başarısını önemli ölçüde düşürebilir. Ayrıca ölçüm aracının doğru sonuçlar vermemesi hemşirelerin ve diğer sağlık çalışanlarının araca duyduğu güvenin azalmasına da neden olabilir (31). Araştırma kapsamında HARİZMİ Düşme Riski Ölçeği'nin negatif öngörü değeri daha yüksek hesaplanmıştır. Pozitif ve negatif öngörü değerleri hastalığın/olayın görülme ve görülmeme olasılıkları hakkında bilgi sağladıkları için bu değeler hastalığın/olayın prevelansından çok etkilenmektedir (27).

Ölçeğin ayırım gücünün bir diğer önemli parametresi ise ROC analizi sonucunda hesaplanan ROC eğrisi altında kalan alan (area under the ROC curve - AUC)'dır. AUC değerinin .50 olması ölçeğin ayırım gücünün tamamen şansa dayalı olduğunu diğer bir deyişle hastaları ayırımda ölçek uygulamak ile yazı tura atmanın farksız olduğunu göstermektedir. Değerin .70'den düşük olması ölçeğin ayırım gücünün "yetersiz", .70 - .80 arasında olması "kabul edilebilir", .80 - .90 arası "çok iyi", .90 - 1.0 arası ise "mükemmel" olduğunu ifade etmektedir (32). Araştırma kapsamında HARİZMİ Düşme Riski Ölçeği için hesaplanan AUC değerinin kabul edilebilir sınır olan .70'nin altında kaldığı görülmektedir. Yöntem ve arkadaşları (2017) tarafından gerçekleştirilen araştırmada da araştırma ile benzer şekilde AUC değeri .70'nin altında hesaplanmıştır (18). Elde edilen bu bilgiler HARİZMİ Düşme Riski Ölçeği'nin ayırım gücünün yetersiz olduğunu destekler niteliktedir. ROC analizi sonucunda farklı kesim noktaları için hesaplanan duyarlık ve özgüllük değerleri incelendiğinde duyarlık (.64) ve özgüllük (.53) değerlerinin daha dengeli olduğu 6 puanının kesme noktası olarak kullanılması önerilebilir.

\section{Kisıtlılıklar}

Araştırma sonuçlarının genellenebilirliği açısından örneklem çeşitliliğinin sağlanmış olması önem arz etmektedir. Ancak araştırma örneklemi ülkemizde yataklı sağlık hizmeti sunulan tüm kurumlardan seçilememiştir. Bu durum araştırma sonuçlarının genellenebilirliği açısından sınırlılık oluşturabilir. Bununla birlikte gerçekleştirilen araştırmalarda sağlık personellerinin tıbbi hata bildirimlerini yeterli düzeyde yapmadığı saptanmıştır $(7,33,34)$. Araştırma kapsamında ise hasta düşmesi vakalarına olay bildirimleri retrospektif incelenerek ulaşılmışıtır. Bu nedenle incelenen hasta düşmesi vakaları gerçek durumu tam olarak yansıtmayabilir ve bu durumda araştırma verilerinin güvenirliği açısından bir sınırlılık oluşturabilir.

\section{Sonuçların Uygulamada Kullanımı}

Araştırma kapsamında HARİZMİ Düşme Riski Ölçeği'nin hastaları düşme riski açısından sınıflandırmadaki yeteneğinin düşük olduğu saptanmıştır. Bu sonuç ölçeğin klinik uygulamalarda kullanılması için ölçeğin pediatrik hastalarda düşmelere neden olduğu saptanan faktörler doğrultusunda yeniden düzenlenerek daha geniş bir örneklemde geçerlik ve güvenirliğinin test edilmesi önerilebilir. Yeniden düzenlenecek maddeler ve ölçeğin puanlamasındaki değişikliklerle doğru bir değerlendirme yapılabilecek, özellikle pediatrik alanda düşme önleyici uygulamaların da etkinliği artabilecektir. 


\section{Bilgilendirme}

Yazarlar araştırmaya katkı oranlarını şu şekilde beyan etmiştir; araştırmanın konusu ve metodolojisinin belirlenmesi ŞSİ, MB, VKB; verilerin toplanması ve işlenmesi VKB, İÇ, verilerin analizi ve yorumlanması ŞSİ, MB, VKB, İÇ, makalenin yazılması ŞSİ, MB, VKB, İÇ. Araştırma için herhangi bir fon desteği alınmamıştır. Araştırmanın bütçesi araştırmacılar tarafından karşılanmıştır. Araştırmacılar arasında herhangi bir çıkar çatı̧̧ası bulunmamaktadır. Araştırma ile ilgili bir üniversitenin girişimsel olmayan araştırmalar etik kurulundan etik kurul onayı alınmıştır (Karar No: 2019/18-40 Tarih: 17/07/2019).

\section{Kaynaklar}

1. Mitchell PH: Defining patient safety and quality care. In: Patient Safety and Quality an Evidence-basedHandbook for Nurses, edited by Hughes RG, Rockville (MD), Agency for Healthcare Research and Quality; 2008:1-6

2. Demir D, Çevik Yöntem S, Yıldırım Sarı H, Bektaş M. Çocuk hastalar için düşme riski tanılama ölçeği'nin geliştirilmesi. Hemşirelikte Eğitim ve Araştırma Dergisi. 2013;10(3):34-41.

3. DiGerolamo K, Davis KF. An Integrative Review of Pediatric Fall Risk Assessment Tools. J Pediatr Nurs. 2017;34(3):23-28.

4. Neiman J, Rannie M, Thrasher J, Terry K, Kahn MG. Development, implementation, and evaluation of a comprehensive fall risk program. J Spec Pediatr Nurs. 2011;16(2):130-139.

5. Kim EJ, Lim JY, Kim GM, Lee MK. Meta-analysis of the Diagnostic Test Accuracy of Pediatric Inpatient Fall Risk Assessment Scales. Child Health Nursing Research. 2019;25(1):56-64.

6. Sağlık Bakanlığı, Sağlıkta Kalite Standartları - Hastane (Versiyon 5, Revizyon-01), Sağlık Hizmetleri Genel Müdürlüğü Sağlıkta Kalite ve Akreditasyon Daire Başkanlığı, 2016; 157-168.

7. Hill-Rodriguez D, Messmer PR, Williams P. D, Zeller RA, Williams AR, Wood M, et al. The Humpty Dumpty Falls Scale: A Case-Control Study. J Spec Pediatr Nurs. 2009;14(1):22-32.

8. Matarese M, Ivziku D, Bartolozzi F, Piredda M, De Marinis MG. Systematic review of fall risk screening tools for older patients in acute hospitals. J Adv Nurs. 2015;71(6):1198-1209.

9. Harvey K, Kramlich D, Chapman J, Parker J, Blades E. Exploring and evaluating five paediatric falls assessment instruments and injury risk indicators: An ambispective study in a tertiary care setting. J Nurs Manag. 2010;18(5):531541.

10. Jamerson PA, Graf E, Messmer PR, Fields HW, Barton S, Berger A, et al. Inpatient falls in freestanding children's hospitals. Pediatric nursing. 2014;40(3):127-135.

11. Chromá J. Risk of falling in pediatric nursing. Central European Journal of Nursing and Midwifery. 2016;7(4):542548.

12. Murray E, Vess J, Edlund BJ. Implementing a pediatric fall prevention policy and program. Pediatric nursing. 2016;42(5):256-260.

13. McNeely HL, Thomason KK, Tong S. Pediatric Fall Risk Assessment Tool Comparison and Validation Study. J Pediatr Nurs. 2018;41(4):96-103.

14. Veras Y, Rogers ML, Smego R, Zonfrillo MR, Mello MJ, Vivier PM. Neighborhood Risk factors for pediatric fallrelatedınjuries: a retrospective analysis of a statewidehospital network. Acad Pediatr. 2019;19(6):677-683.

15. Poe SS, Dawson PB, Cvach M, Burnett M, Kumble S, Lewis M, et al. The Johns Hopkins Fall Risk Assessment Tool. J Nurs Care Qual. 2018;33(1):10-19.

16. Petitpierre NJ, Trombetti A, Carroll I, Michel JP, Herrmann FR. The FIM instrument to identify patients at risk of falling in geriatric wards: a 10-year retrospective study. Age Ageing. 2010;39(3):326-331.

17. Ivziku D, Matarese M, Pedone C. Predictive validity of the Hendrich fall risk model II in an acute geriatric unit. Int J Nurs Stud. 2011;48(4):468-474.

18. Yöntem S, Gök D, Yıldırım Sarı H, Aydınlık Güntürkün F. BUÇH II Çocuk hastalarda düşme riski skoru: Harizmi ve BUÇH ölçekleri ile karşılaştırılması. İzmir Dr. Behçet Uz Çocuk Hastanesi Dergisi. 2017;7(2):105-112.

19. Şencan H. Sosyal ve Davranışsal Ölçümlerde Güvenirlik ve Geçerlik. Ankara, Turkey: Seçkin Ofset; 2005; 250-260.

20. Flahault A, Cadilhac M, Thomas G. Sample size calculation should be performed for design accuracy in diagnostic test studies. J Clin Epidemiol. 2005;58(8):859-862.

21. Akgül A. Tıbbi Araştırmalarda İstatistiksel Analiz Teknikleri ‘SPSS Uygulamaları’. 3. Basım, Emek Ofset; 2005; 180396.

22. Gözüm S, Aksayan S. Kültürlerarası ölçek uyarlaması için rehber II: Psikometrik özellikler ve kültürlerarası karsılastırma. Hemsirelikte Arastırma Gelistirme Dergisi 2003;5(1):3-14.

23. Nunnally C, Bernstein H, Psychometric Theory. 3th ed. McGraw-Hill; 1994; 303-305.

24. Razmus I, Davis D. The epidemiology of falls in hospitalized children. Pediatric Nursing. 2012;38(1):31-35.

25. Kingston A, Bryant, T, Speer K. Pediatrics falls benchmarking collaborative. J Nurs Adm. 2010;40(6):287-292.

26. Schaffer PL, Darasieh NM, Daum L, Mendez E, Lin L, Huth MM. Pediatric inpatient falls and injuries: A descriptive analysis of risk factors. J Spec Pediatr Nurs. 2012;17(1):10-18.

27. Akobeng AK. Understanding diagnostic tests 1: sensitivity, specificity and predictive values. Acta Paediatrica. 2007;96(3):338-341.

28. Beak S, Piao J, Jin Y, Lee SM. Validity of the Morse Fall Scale implemented in an electronic medical record system. J Clin Nurs. 2013;23(17-18): 434-244.

29. Chow SKY, Lai CKY, Wong TKS, Suen LKP, Kong SKF, Chan CK, et al. Evaluation of the Morse Fall Scale: Applicability in Chinese hospital populations. Int J Nurs Stud. 2007;44(4):556-565. 
30. Watson BJ, Salmoni AW, Zecevic AA. The use of the Morse Fall Scale in an acute care hospital. Clin Nurs Stud. 2016;4(2):32-40.

31. Klinkenberg WD, Potter P. Validity of the Johns Hopkins Fall Risk Assessment Tool for Predicting Falls on Inpatient Medicine Services. J Nurs Care Qual. 2017;32(2):108-113.

32. Hajian-Tilaki K. Receiver operating characteristic (ROC) curve analysis for medical diagnostic test evaluation. Caspian J Intern Med. 2013;4(2):627-635.

33. Soydemir D, Seren Intepeler S, Mert H. Barriers to medical error reporting for physicians and nurses. West J Nurs Res. 2017;39(10):1348-1363.

34. Shorr RI, Mion LC, Chandler AM, Rosenblatt LC, Lynch D, Kessler LA. Improving the capture of fall events in hospitals: combining a service for evaluating inpatient falls with an incident report system. J Am Geriatr Soc. 2008;56(4):701-704. 